\title{
CARACTERIZAÇÃO DA XANTANA PRODUZIDA POR Xanthomonas campestris pv. mangiferaeindicae IBSBF 1230 UTILIZANDO DIFERENTES FONTES DE CARBONO
}

\author{
R. A. TRINDADE ${ }^{1}$, A. P. MUNHOZ ${ }^{1}$ e C. A. V. BURKERT ${ }^{1}$ \\ ${ }^{1}$ Universidade Federal do Rio Grande, Escola de Química e Alimentos \\ E-mail para contato: rtrindade@furg.br
}

\begin{abstract}
RESUMO - O objetivo do presente trabalho foi avaliar o impacto do uso do glicerol residual (GR) em substituição total ou parcial da sacarose (S) utilizada como fonte de carbono no meio de cultivo convencional, verificando os efeitos em algumas propriedades da goma xantana produzida por Xanthomonas campestris pv. mangiferaeindicae IBSBF 1230. Os cultivos para obtenção da goma foram realizados em triplicata, em frascos agitados a $28^{\circ} \mathrm{C}, 200 \mathrm{rpm}$ por $48 \mathrm{~h}$, utilizando como fontes de carbono S, GR e uma mistura de ambas (SGR) na proporção de 1:1 m/m. A goma foi obtida por centrifugação do meio, adição de etanol $(1: 4 \mathrm{v} / \mathrm{v})$ para precipitação repouso por $24 \mathrm{~h}$, nova centrifugação e secagem em estufa a $50^{\circ} \mathrm{C}$ até peso constante. A viscosidade aparente e o índice de emulsificação $\left(\mathrm{IE}_{24}\right)$ foram determinados em suspensões contendo $5 \%(\mathrm{~m} / \mathrm{m})$ da xantana produzida com as três diferentes fontes de carbono, utilizando para o $\mathrm{IE}_{24}$ diferentes óleos vegetais. O comportamento térmico foi analisado por Calorimetria Exploratória Diferencial (DSC). O comportamento reológico foi similar para as xantanas produzidas nos diferentes meios, entretanto a viscosidade inicial foi maior com o meio S (637 cP), seguido de SGR $(279 \mathrm{cP})$ e $\mathrm{GR}(60 \mathrm{cP}) . \mathrm{O} \mathrm{IE}_{24}$ foi superior quando utilizado o óleo de milho, atingindo valores de 97, 72 e $64 \%$ em S, SGR e GR, respectivamente. Desta forma, pode-se afirmar que a mudança na fonte de carbono afeta estas propriedades.
\end{abstract}

\section{INTRODUÇÃO}

A bactéria fitopatogênica Xanthomonas campestris é responsável pela produção da goma xantana (Luvielmo; Scamparini, 2009). De acordo com Food and Drugs Administration (FDA), dos Estados Unidos, e com a legislação brasileira, através da Agência Nacional de Vigilância Sanitária (Anvisa, 1999), a goma xantana sintetizada por Xanthomonas campestris é aprovada para o uso alimentar.

Essa bactéria é excepcional na produção de significativas quantidades deste exopolissacarídeo (EPS), não produzindo outros polímeros, podendo assim alcançar conversões muito elevadas de xantana (Freitas et al., 2011). É facilmente cultivada em laboratório, por ser aeróbica e microaerófila, com temperatura ótima de crescimento entre $25-30^{\circ} \mathrm{C}$. Possui crescimento rápido, produzindo turbidez no meio com 2-3 dias de cultivo (Druzian; Pagliarini, 2007), e um pH ótimo entre 6 e 8 (Donot et al., 2012).

A goma xantana ocupa um lugar de destaque por suas propriedades reológicas diferentes das 


\section{9 a 22 de outubro de 2014 \\ Florianópolis/SC}

outras gomas microbianas, tais como um elevado grau de pseudoplasticidade, viscosidade elevada mesmo em baixas concentrações, solubilidade e estabilidade em soluções ácidas e alcalinas, resistência à degradação em elevadas temperaturas e em diferentes níveis de pH (Faria et al., 2011). Sendo assim, sua aplicação na indústria de alimentos, farmacêutica e petroquímica é de extrema importância (Mesomo, 2007).

Por outro lado, de acordo com o PNPB (2012), entrou em vigor a Lei n⿳0 11.097 de 13 de janeiro de 2005, que estabeleceu a obrigatoriedade da mistura do biodiesel ao diesel. O glicerol é o principal coproduto gerado na produção do biodiesel, sendo aproveitado em vários setores industriais. Entretanto, com o amadurecimento do mercado, o glicerol residual tem sido gerado em proporções maiores que a demanda. Desta forma, a produção deste biocombustível em larga escala pode se tornar um problema em relação à disposição dos coprodutos gerados (Silveira, 2007).

Neste contexto, este trabalho objetiva avaliar o impacto do uso de GR em substituição total ou parcial da $\mathrm{S}$ utilizada como fonte de carbono no meio de cultivo convencional, verificando os efeitos da viscosidade, das propriedades térmicas e o índice de emulsificação da goma xantana produzida por Xanthomonas campestris pv. mangiferaeindicae IBSBF 1230.

\section{MATERIAL E MÉTODOS}

\subsection{Micro-organismo}

A bactéria Xanthomonas campestris pv. mangiferaeindicae IBSBF 1230 foi obtida da Coleção de Culturas de Fitobactérias do Instituto Biológico (IBSBF) - Campinas - SP, Brasil.

\subsection{Glicerol Residual}

O glicerol residual proveniente da obtenção de biodiesel a partir do óleo de soja por via metanólica foi fornecido pela empresa BS Bios Indústria e Comércio de Biodiesel Sul Brasil S/A (Passo Fundo - RS). O glicerol residual continha $81,92 \%(\mathrm{~m} / \mathrm{m})$ de pureza, de acordo com laudo fornecido pela própria empresa, sendo que a quantidade adicionada nos meios levou em conta sua composição, a fim de resultar na concentração desejada do substrato (glicerol) nos meios de cultivo.

\subsection{Re-hidratação da cultura liofilizada}

A cultura acondicionada em ampola de vidro foi rompida em condições estéreis. Adicionandose 5 gotas do Caldo Nutriente, incuband0-se a $28^{\circ} \mathrm{C}$ durante $60 \mathrm{~min}$. Transcorrido esse tempo, a suspensão foi transferida para placas de Petri contendo meio Ágar Nutriente (5 g.L ${ }^{-1}$ peptona; 6 g.L $\mathrm{L}^{-1}$ $\mathrm{NaCl} ; 1,5$ g. $\mathrm{L}^{-1}$ extrato de carne; 1,5 g. $\mathrm{L}^{-1}$ extrato de levedura; 15 g. $\mathrm{L}^{-1}$ ágar) e incubadas a $28^{\circ} \mathrm{C}$ por $48 \mathrm{~h}$ (IBSBF, 2013).

\subsection{Manutenção da cultura microbiana}

A partir da cultura re-hidratada foram realizados repiques sucessivos, sendo utilizado o meio YM (Yeast Malt), composto por (g. $\left.\mathrm{L}^{-1}\right): 3$ extrato de levedura; 3 extrato de malte; 5 peptona; 20 
glicose; 10 ágar; pH 7,2 (Mesomo, 2007). A bactéria foi incubada para crescimento celular em estufa com temperatura controlada $\left(28^{\circ} \mathrm{C}\right)$ por $48 \mathrm{~h}$. As cepas foram mantidas refrigeradas, sendo realizados repiques mensais.

\subsection{Preparo do inóculo}

O inóculo foi preparado partindo de um tubo contendo a cultura microbiana reativada, sendo raspada com $10 \mathrm{~mL}$ de água peptonada $0,1 \%$, a fim de resultar em uma suspensão de células. Esta foi transferida para $90 \mathrm{~mL}$ de meio apropriado contido em frasco Erlenmeyer de $500 \mathrm{~mL}$. Os frascos foram mantidos em incubadora refrigerada com agitação orbital (Tecnal TE - 424, Brasil) a $28{ }^{\circ} \mathrm{C}$ e $150 \mathrm{rpm}$, até atingir uma densidade ótica (DO 560nm) de 2,0.

\subsection{Cultivos em frascos agitados}

Foram realizados cultivos em frascos Erlenmeyer de $500 \mathrm{~mL}$. Suspensão microbiana correspondente a $10 \%$ do volume total $(10 \mathrm{~mL})$ foi transferida para $90 \mathrm{~mL}$ de meio de cultivo, a fim de totalizar $100 \mathrm{~mL}$ de meio. Os frascos foram mantidos em incubadora refrigerada com agitação orbital (Tecnal TE-424, Brasil), na temperatura de $28^{\circ} \mathrm{C}$ e $200 \mathrm{rpm}$ de agitação.

Nesta etapa, foi utilizado o meio composto em g.L $\mathrm{L}^{-1}: 50$ fonte de carbono; 2,5 $\mathrm{NH}_{4} \mathrm{H}_{2} \mathrm{PO}_{4} ; 5,0$ $\mathrm{K}_{2} \mathrm{HPO}_{4} ; 0,006 \mathrm{H}_{3} \mathrm{BO}_{3} ; 2\left(\mathrm{NH}_{4}\right)_{2} \mathrm{SO}_{4} ; 0,0024 \mathrm{FeCl}_{3} ; 0,002 \mathrm{CaCl}_{2} .2 \mathrm{H}_{2} \mathrm{O} ; 0,002 \mathrm{ZnSO}_{4} ; \mathrm{pH}$ 7,0. Como fontes de carbono foram usadas a sacarose $(\mathrm{S})$, o glicerol residual (GR), considerando sua composição a fim de resultar na concentração desejada do substrato, e uma mistura de ambos na proporção de 1:1 m/m, totalizando a concentração indicada (SGR), como sugerido por Reis et al. (2010).

\subsection{Recuperação da xantana}

A recuperação da xantana do meio foi realizada através da centrifugação do meio a $3400 \mathrm{xg}$ por 30 min a $4{ }^{\circ} \mathrm{C}$, para remoção de células, seguido de precipitação do EPS pela adição de etanol 96,4 ${ }^{\circ} \mathrm{GL}(1: 4 \mathrm{v} / \mathrm{v})$, repouso por $24 \mathrm{~h} \mathrm{a} 4^{\circ} \mathrm{C}$, sendo novamente centrifugado por $30 \mathrm{~min}$, sob refrigeração (4 ${ }^{\circ} \mathrm{C}$ ). A secagem foi realizada em estufa a $50{ }^{\circ} \mathrm{C}$ até peso constante (Mesomo, 2007).

\subsection{Solubilização das amostras}

Para o preparo das amostras tanto para determinação da viscosidade quanto para atividade emulsificante, foi realizado o procedimento de acordo com Xuewu et al., (1996), onde o EPS foi diluído, na concentração de $5 \%(\mathrm{~m} / \mathrm{m})$, em água destilada, agitado por $2 \mathrm{~h}$, seguido de aquecimento a $60{ }^{\circ} \mathrm{C}$ por $20 \mathrm{~min}$.

\subsection{Viscosidade}

Para determinação da viscosidade da goma xantana produzida, as amostras solubilizadas foram mantidas na temperatura ambiente por $24 \mathrm{~h}$. Foi utilizado um reômetro digital Brookfield (Estados Unidos), acoplado a um banho-maria a $25^{\circ} \mathrm{C}$, com adaptador para pequenas amostras, determinando- 
se as curvas de viscosidade aparente (cP) em função da taxa de cisalhamento $\left(\mathrm{s}^{-1}\right)$. As leituras foram realizadas em intervalos de $15 \mathrm{~s}$ e a taxa de cisalhamento variou de 5 a $100 \mathrm{~s}^{-1}$ (Mesomo, 2007). O spindle escolhido foi CP51.

\subsection{0 Índice de emulsificação}

$\mathrm{O}$ índice de emulsificação ( $\left.\mathrm{IE}_{24}\right)$ foi determinado para as gomas produzidas com as diferentes fontes de carbono (S, SGR e GR), usando como referência a goma arábica comercial, baseando-se no método de Cooper e Goldemberg (1987). Foram utilizados diferentes óleos vegetais: milho, girassol, soja, canola e azeite de oliva. A suspensão de goma $(5 \% \mathrm{~m} / \mathrm{m})$ e cada óleo foram adicionados na proporção de 2:3 v/v, em tubos de ensaio com rosca e logo após os tubos foram agitados em vórtex durante $2 \mathrm{~min}$. Após $24 \mathrm{~h}$ de repouso, foi medida a altura da camada emulsionada e a altura total da camada líquida.

$$
\begin{aligned}
& \text { O IE } E_{24} \text { foi calculado de acordo com a equação abaixo: } \\
I E_{24}= & \frac{\text { altura da camada emulsionada } .100 \%}{\text { altura total }}
\end{aligned}
$$

\subsection{Calorimetria exploratória diferencial (DSC)}

Para o estudo das propriedades térmicas das gomas, foi realizada a Calorimetria Exploratória Diferencial (DSC). Nesta técnica, mede-se o fluxo de calor entre a amostra e um material termicamente inerte enquanto ambos são submetidos a uma variação de temperatura, sendo possível a avaliação das modificações do estado físico das amostras, como fusão e transição cristalina, pois ocorre liberação de calor (Horn, 2008).

As curvas de DSC foram obtidas no equipamento modelo DSC-60 (Shimadzu, Japão), sob atmosfera dinâmica de nitrogênio com vazão de $50 \mathrm{~mL} \cdot \mathrm{min}^{-1}$, utilizando uma taxa de aquecimento de $10{ }^{\circ} \mathrm{C} \cdot \mathrm{min}^{-1}$, com variação da temperatura de 40 a $250^{\circ} \mathrm{C}$, com suporte de alumínio hermético, sendo pesadas de 3-5 mg de amostra.

\section{RESULTADOS E DISCUSSÃO}

\subsection{Viscosidade}

As propriedades reológicas das gomas influenciam diretamente no processamento, aplicação e até mesmo nos projetos de equipamentos (Mesomo, 2007). Para verificar a qualidade do biopolímero sintetizado quando S, GR e SGR foram utilizados como fonte de carbono foi determinada a viscosidade de uma solução aquosa a $5 \%(\mathrm{~m} / \mathrm{v})$.

A figura 1 apresenta a comportamento da viscosidade aparente (cP) em função da taxa de cisalhamento $\left(\mathrm{s}^{-1}\right)$ para as gomas produzidas por $X$. campestris $\mathrm{pv}$. mangiferaeindicae IBSBF 1230 com as diferentes fontes de carbono utilizadas. 


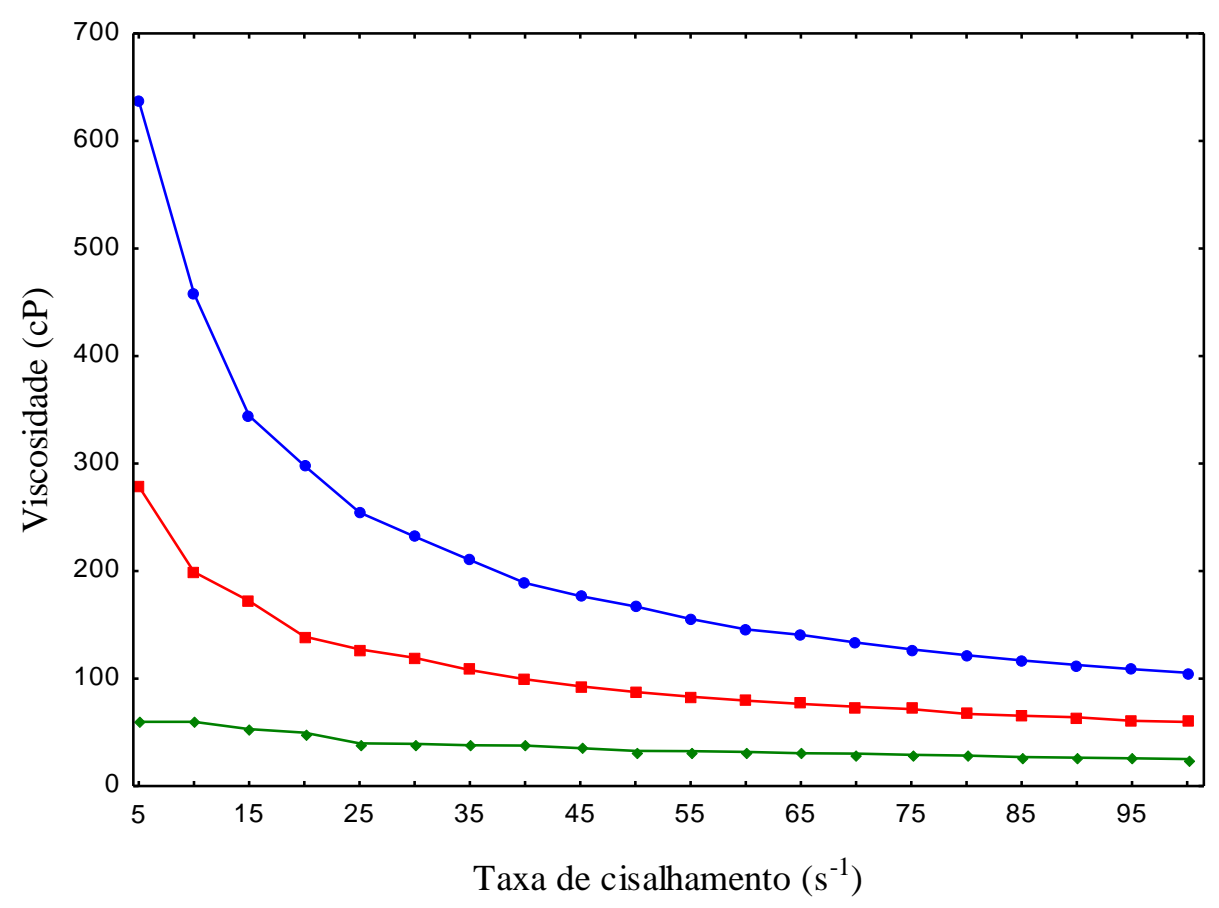

Figura 1 - Viscosidade da goma xantana (solução aquosa $5 \% \mathrm{~m} / \mathrm{v}$ ) produzida por Xanthomonas campestris pv. mangiferaeindicae IBSBF 1230. (•) S, (๘) SGR e (») GR.

De acordo com a figura 1, quando compara-se a viscosidade aparente das gomas sintetizadas com as diferentes fontes de carbono, pode-se perceber que uma maior viscosidade inicial foi encontrada para bactéria $X$. campestris pv. mangiferaeindicae IBSBF 1230 quando utilizada $\mathrm{S}$ como fonte de carbono (637 cP), seguido de SGR (279 cP) e GR (60 cP), demonstrando assim um comportamento pseudoplásticos, onde a viscosidade diminui com o aumento da taxa de cisalhamento (Luvielmo; Scamparini, 2009; Mesomo, 2007).

Reis et al. (2010) compararam a viscosidade aparente de biopolímeros produzidos por Xanthomonas sp C1 e C9 tendo S, GR e SGR como fontes de carbono, utilizando soluções aquosas 3 $\%$ a $25^{\circ} \mathrm{C}$ e $0,257 \mathrm{~s}^{-1}$. Como resultados, foram encontrados valores para viscosidade inicial de 941 , 143 e $140 \mathrm{cP}$, respectivamente para S, SGR e GR, quando utilizado a Xanthomonas sp C1. No mesmo trabalho, os autores verificaram um comportamento diferente com a goma produzida por Xanthomonas sp C9, com um maior valor de viscosidade encontrado ao utilizar SGR (aproximadamente $93 \mathrm{cP}$ ) do que $\mathrm{S}$ (aproximadamente $40 \mathrm{cP}$ ) nas mesmas condições anteriores.

As propriedades reológicas dos polissacarídeos dependem da concentração da solução aquosa, do massa molecular, bem como do processo de produção do EPS, como composição de meio, $\mathrm{pH}$ e temperatura (Reis et al., 2010).

\section{2 Índice de Emulsificação ( $\left(\mathrm{IE}_{24}\right)$}

Na tabela 1 apresenta-se os resultados da capacidade emulsificante da goma xantana em formar e estabilizar emulsões em 24 h, utilizando diferentes óleos vegetais e a goma arábica comercial. 
Tabela 1 - $\mathrm{IE}_{24}$ para goma xantana sintetizada com diferentes fontes de carbono em comparação com a goma arábica (comercial)

\begin{tabular}{|c|c|c|c|c|}
\hline \multicolumn{5}{|c|}{ Indice de emulsificação (\%) } \\
\hline \multicolumn{4}{|c|}{ Goma xantana } & \multirow{2}{*}{$\begin{array}{c}\text { Goma arábica } \\
\text { (comercial) }\end{array}$} \\
\hline & $\mathrm{S}$ & SGR & GR & \\
\hline Òleo de soja & $11,1 \pm 0,1^{b, D}$ & $5,6 \pm 0,1^{\mathrm{d}, \mathrm{E}}$ & $8,3 \pm 0,2^{\mathrm{c}, \mathrm{E}}$ & $73,1 \pm 1,4^{\mathrm{a}, \mathrm{A}}$ \\
\hline Óleo de canola & $52,9 \pm 0,0^{\mathrm{c}, \mathrm{C}}$ & $61,8 \pm 1,1^{\mathrm{a}, \mathrm{B}}$ & $58,0 \pm 1,3^{\mathrm{b}, \mathrm{B}}$ & $20,8 \pm 2,3^{\mathrm{d}, \mathrm{E}}$ \\
\hline Óleo de girassol & $56,4 \pm 0,4^{\mathrm{a}, \mathrm{B}}$ & $53,0 \pm 0,13^{b, C}$ & $46,5 \pm 0,3^{\mathrm{c}, \mathrm{C}}$ & $27,6 \pm 0,5^{\mathrm{d}, \mathrm{C}}$ \\
\hline Óleo de milho & $96,8 \pm 0,2^{\mathrm{a}, \mathrm{A}}$ & $71,6 \pm 1,7^{\mathrm{b}, \mathrm{A}}$ & $64,1 \pm 1,1^{\mathrm{c}, \mathrm{A}}$ & $24,2 \pm 0,0^{\mathrm{d}, \mathrm{D}}$ \\
\hline Azeite de oliva & $11,3 \pm 0,1^{\mathrm{b}, \mathrm{D}}$ & $6,4 \pm 0,2^{\mathrm{d}, \mathrm{D}}$ & $8,5 \pm 0,2^{\mathrm{c}, \mathrm{D}}$ & $66,3 \pm 2,9^{\mathrm{a}, \mathrm{B}}$ \\
\hline
\end{tabular}

*Letras minúsculas diferentes para um mesmo óleo indicam que há diferença significativa entre as gomas a $95 \%$ de confiança $(\mathrm{p}<0,05)$. Letras maiúsculas diferentes para uma mesma goma indicam que há diferença significativa entre os óleos a $95 \%$ de confiança $(\mathrm{p}<0,05)$.

De acordo com a figura 2 pode-se perceber que o $\mathrm{IE}_{24}$ para o óleo de milho foi maior quando a goma com S como fonte de carbono foi utilizada, sendo este 96,8 \%, seguido da goma SGR (71,6\%) e GR $(64,1 \%)$. Um comportamento similar foi observado para o óleo de girassol, com $\mathrm{IE}_{24}$ de $56,4 \%$ para S, diferindo significativamente quando utilizado SGR e GR como fonte de carbono. O óleo de canola apresentou um maior $\mathrm{IE}_{24}$ quando a mistura SGR foi utilizada como fonte de carbono $(61,8$ $\%)$, seguido por GR $(58,0 \%)$ e S $(52,9 \%)$. Quando avaliado o azeite de oliva, o comportamento foi bem diferente em relação aos outros óleos.

Iyer et al. (2006) investigaram o EPS produzido pela bactéria Enterobacter cloaceae em óleo de parafina, algodão, coco, jojoba, amendoim e girassol, com concentração de 1 g.L $\mathrm{L}^{-1}$ e encontraram um $\mathrm{IE}_{24}$ para os óleos de parafina, coco e algodão de $60 \%$, para o óleo de jojoba $65 \%$, girassol $75 \%$, sendo o maior $\mathrm{IE}_{24}$ encontrado para o óleo de amendoim (95\%). Avaliaram também o $\mathrm{IE}_{24}$ nas mesmas concentrações, para as gomas comerciais xantana e arábica, encontrando 33 e $61 \%$, respectivamente.

\subsection{Calorimetria Exploratória Diferencial (DSC)}

A figura 3 apresenta a analise de Calorimetria Exploratória Diferencial (DSC) para as gomas xantana produzidas com S, SGR e GR como fontes de carbono. 


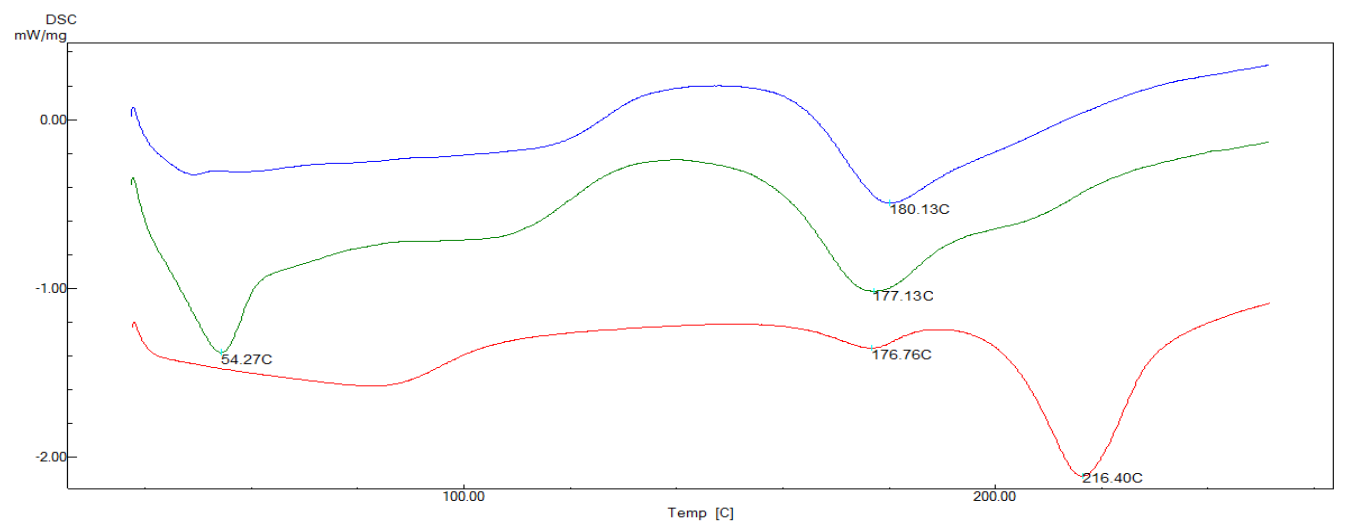

Figura 2 - DSC para goma xantana. (-) S, (-) SGR e (-) GR.

As curvas de DSC obtidas para goma xantana produzidas com SGR e GR apresentaram uma temperatura de fusão muito similares $\left(180,13{ }^{\circ} \mathrm{C}\right.$ e $\left.177,13{ }^{\circ} \mathrm{C}\right)$, comportamento este também encontrado pela goma xantana com S, sendo o pico menos acentuado, na temperatura de $176,13{ }^{\circ} \mathrm{C}$ e um maior pico de fusão encontrado quando atingiu-se a temperatura de $216,40{ }^{\circ} \mathrm{C}$. Marques et al. (2012) encontraram para goma xantana produzida utilizando a sacarose como fonte de carbono uma temperatura de fusão de $162{ }^{\circ} \mathrm{C}$, resultado este similar ao encontrado neste trabalho. Ao avaliar a goma produzida com GR pode-se perceber ainda um pico na temperatura de $54,27{ }^{\circ} \mathrm{C}$, que pode ter sido ocasionado por algum contaminante termolábil. As dieferentes curvas observadas podem estar relacionadas a diferentes estruturas das gomas xantanas produzidas.

\section{CONCLUSÃO}

As xantanas produzidas por $X$. campestris pv mangiferaeindicae IBSBF 1230 utilizando diferentes fontes de carbono (S, SGR e GR) apresentaram diferenças quanto à viscosidade aparente de suspensões a $5 \% \mathrm{~m} / \mathrm{v}$, propriedades térmicas (DSC) bem como quanto à formação de emulsões com diferentes óleos vegetais, indicando que a mudança na fonte de carbono afeta estas propriedades, fato provavelmente associado a mudanças estruturais dos EPSs sintetizados. Desta forma, pode-se afirmar que a substituição total ou parcial de S por GR é possível, entretanto esta substituição deve ser considerada com cautela, pois influi nas propriedades diretamente ligadas à aplicação.

\section{AGRADECIMENTOS} de bolsa.

Os autores agradecem à FAPERGS e ao CNPq pelo apoio financeiro e a CAPES pela concessão

\section{REFERÊNCIAS}

ANVISA. Ministério da Saúde. Agência Nacional da Vigilância Sanitária. Resolução no 386. Diário Oficial da União. Brasilía, 05 de ago. 1999. Disponível em: http:/www.anvisa.gov.br/legis/resol/386_99.htm. Acesso em: 01 de mar de 2014. 
COOPER DG, GOLDENBERG BG. Surface active agents of two Bacillus species. Appl Environ. Microbiol., v. 53, p 224-9, 1987.

DONOT, F.; FONTANA, A.; BACCOU, J.C.; SCHORR-GALINDO, S. Microbial exopolysaccharides: main examples of synthesis, excretion, genetics and extraction. Carbohyd. Polym., v. 87, p. 951-962, 2012.

DRUZIAN, J.I.; PAGLIARINI, A.P. Produção de goma xantana por fermentação do resíduo de suco de maçã. Ciência Tecnol. Alime., v. 27, n. 1, p. 26-31, 2007.

FARIA, S.; PETKOWICS, C. L.; MORAIS, S.; HERNANDEZ-TERRONES, M.G.; RESENDE, M. M. ; FRANCA, F. P. ; CARDOSO, V. L. Characterization of xanthan gum produced from sugar cane broth. Carbohyd. Polym., v. 86, p.469-476, 2011.

FREITAS, F.; ALVES, V.D.; REIS, M.A.M. Advances in bacterial exopolysaccharides: from production to biotechnological applications. Trends Biotechnol., v. 29, p. 388-398, 2011.

HORN, M.M. Obtenção e caracterização de hidrogéis de quitosana, xantana e colágeno aniônico. 2008. 73f. Dissertação (Mestrado em Ciência - Química analítica) - Universidade de São Paulo (USP), São Carlos.

IBSBF - Coleção de Cultura de Fitobactérias do Instituto Biológico. Instruções para rehidratação das culturas. Campinas, São Paulo, 2013.

IYER, A.; MODY, K.; JHA, B. Emulsifying properties of a marine bacterial exopolysaccharide. Enzyme Microb. Tech., v. 38, p. 220-222, 2006.

LUVIELMO, M.M.; SCAMPARINI, A.R.P. Goma xantana: produção, recuperação, propriedades e aplicação. Estudos Tecnológicos, v. 5, p. 50-67, 2009.

MESOMO, M.C. Produção de goma xantana em biorreator utilizando meio à base de soro de queijo. 2007. 81 f. Dissertação (Mestrado em Engenharia de Alimentos) - Universidade do Alto Uruguai e das Missões (URI), Erechim.

REIS, E.C.; ALMEIDA, M.; CARDOSO, J.C.; PEREIRA, M.A.; OLIVEIRA, C.B.Z.; VENCESCAU, E.M.; DRUZIAN, J.I.; MARIANO, R.; PADILHA, F.F. Biopolymer synthesized by strains of Xanthomonas sp isolate from Brazil using biodiesel-waste. Macromol. Symp., v. 296, p. 347-353, 2010.

SILVEIRA, L. Glicerina gerada na produção do biodiesel terá novos usos. 2007. Biodieselbr online. Disponível em: 〈http://www.biodieselbr.com>. Acesso em 05 de janeiro de 2014.

XUEWU; Z.; XIN, L.; DEXIANG, G.; WEI; Z.; TONG, X; YONGHONG, M. Rheological models for xanthan gum. J. Food Eng., v. 27, p. 203-209, 1996. 